\section{Maturity-onset diabetes of the young (MODY) at least ten times more common in Europe than previously assumed?}

Dear Sir,

From 1986 to 1994 we screened 2,064 diabetic patients $(1,798$ with non-insulin-dependent (NIDDM) and 266 with insulindependent diabetes (IDDM)) in the German district of Hesse. In this group we found 38 patients ( 22 male, 16 female) fulfilling the criteria for MODY (maturity-onset diabetes of the young) established by Tattersall and Fajans [1] (diagnosis before the age of 25 years and treated successfully with diet or oral drugs for 5 years). All these patients had at least one first-degree relative with diabetes mellitus. MODY has become particularly interesting to study recently because it may serve as a genetic model for NIDDM, a major metabolic disorder rising in incidence worldwide $[2,3]$.

In 1981 Panzram and Adolph [4] published the results of a survey of 40,927 East German diabetic patients from whom they had collected a subgroup of 58 MODY patients $(0.14 \%)$. According to our results MODY seems to be 12.9 times more frequent $(1.8 \%$ of all diabetic patients) and even 15 times more frequent with regard to the NIDDM group (2.1\%). Since such a vast difference in epidemiological data from neighbouring areas of Germany appears to be unlikely, MODY may not be quite so rare as previously estimated. These data appear to be not only important for the epidemiologist but also for the

Corresponding author: Dr. H.M.Ledermann, EleonorenKlinik, D-64678 Lindenfels-Winterkasten, Germany

\section{Testing parents of NIDDM patients}

Dear Sir,

Mitchell et al. [1] have recently reported data which fail to confirm that of a number of other independent research groups who concurred that non-insulin-dependent diabetes mellitus (NIDDM) appears to be more common amongst mothers than fathers of affected individuals [2,3]. A major drawback of the previous studies has been their retrospective nature, and the attempt by Mitchell et al. [1] to test parents for diabetes is to be commended. This approach is limited by the ability

Corresponding author: Dr. J.C. Alcolado, Department of Medicine, University Hospital of Wales, Heath Park, Cardiff CF4 4XW, UK patient himself who may seek medical advice concerning family planning, a relevant issue in a highly hereditary disease.

We also found that MODY patients had a much worse diabetes education record compared with IDDM patients with their more dramatic onset of diabetes, mostly also at a young age. Only $10.5 \%$ MODY diabetic patients were adequately educated in the years from 1986-1989 as compared with $27.6 \%$ IDDM patients. During the last 4 years the respective figures have risen to $57.7 \%$ for IDDM patients and only $26.3 \%$ for MODY patients. As education is widely accepted to be the basis of diabetes treatment this moderate improvement cannot be regarded as sufficient.

We conclude that MODY is much more common in central Europe than has been previously assumed and should be better recognised, understood and treated.

Yours sincerely,

H.M. Ledermann

\section{References}

1. Tattersall RB, Fajans SS (1975) A difference between the inheritance of classical juvenile onset type diabetes in young people. Diabetes 24: $44-53$

2. McCarthy MI, Hitman GA, Shields DC et al. (1994) Family studies of non-insulin-dependent diabetes mellitus in South Indians. Diabetologia 37: 1221-1230

3. Cook JTE, Shields DC, Page RCL et al. (1994) Segregation analysis of NIDDM in Caucasian families. Diabetologia 37: $1231-1240$

4. Panzram G, Adolph W (1981) Heterogeneity of maturity onset diabetes at young age (MODY). Lancet 2: 986

to find available parents since NIDDM is a disease of late onset and many parents will have died. It is not surprising that the paper by Mitchell et al. [1] fails to find evidence for maternal transmission given the small numbers of subjects who were available for study.

Firstly, only 29 unrelated diabetic probands were recruited from San Antonio. Although it is not clear from the paper, we assume the 54 diabetic sibships must also have included some of the 33 randomly ascertained probands. It is vital that all 54 diabetic sibships are separate, not related and belong to different pedigrees. For this to be the case, 25 of the 33 randomly ascertained probands must have led to the discovery of a diabetic sibship. We suspect this may not have been the case and that the 54 diabetic sibships include members from several generations of the same pedigree. If diabetes is either maternally or paternally inherited through a pedigree, counting the same pedigree twice will severely bias the results. In our original pa- 
per, we made attempts to exclude all related probands. We question the concept of the diabetic sibship; these studies should be based on numbers of separate, unrelated pedigrees.

A second interesting point to emerge from Mitchell et al.'s [1] paper is that the prevalence of diabetes in both mothers and fathers of diabetic probands is over $60 \%$. This is greatly in excess of the values obtained by ourselves $(36 \%$ mothers, $15 \%$ fathers) and the CODIAB group [2] (33\% mothers, $17 \%$ fathers). Although we are not told the age at which glucose tolerance testing was carried out in the parents, we can assume that the figure of $60 \%$ will be an under-estimate increasing with time as parents get older. The figure for parental-offspring diabetic concordance thus begins to approach that seen in some studies on twins $[4,5]$. This again suggests that significant bias is occurring, probably due to the use of related diabetic sibships. It would be interesting to know whether the $30 \%$ diabetes prevalence amongst parents of non-diabetic sibships is significantly greater than the prevalence in an unselected population from the Barrio in San Antonio.

The ideal experiment would be to test both parents of a group of unrelated diabetic probands. Mitchell et al. were only able to test both parents in 18 of 54 diabetic sibships. In order to reach the level of statistical significance of our original publication, we required the family history of 173 unrelated diabetic probands. Even if only 9 of the 28 tested fathers (as opposed to the 18 reported) had been diabetic, statistical significance would not have been reached, although twice as many mothers as fathers would have been affected in percentage terms. Whilst any attempt at studying parents directly is to be encouraged, a study of the design and size of Mitchell et al's [1] would have been most unlikely to confirm a maternal effect in the transmission of diabetes. The data neither support nor refute the hypothesis.

Yours sincerely,

R. Alcolado, J.Gagg, A.W.Thomas, E.J.Sherratt, J.C. Alcolado

\section{References}

1. Mitchell BD, Kammerer CM, Reinhart LJ, Stern MP, MacCluer JW (1995) Is there an excess in maternal transmission of NIDDM? Diabetologia 38: 314-317

2. Alcolado JC, Alcolado R (1991) Importance of maternal history of non-insulin-dependent diabetic patients. BMJ 302: $1178-1180$

3. Thomas F, Balkau B, Vauzelle-Kervroedan F, Papoz L, and the CODIAB Study Group (1994) Maternal effect and familial aggregation in NIDDM. Diabetes 43: 63-67

4. Newman B, Selby JV, King MC, Slemenda C, Fabsitz R, Friedman GD (1987) Concordance for type 2 (non-insulindependent) diabetes mellitus in male twins. Diabetologia 30: 763-768

5. Kaprio J, Tuomilehto J, Koskenvuo M et al. (1992) Concordance for type 1 (insulin-dependent) and type 2 (non-insulin-dependent) diabetes mellitus in a population-based cohort of twins in Finland. Diabetologia 35: 1060-1067

\section{Response from the authors}

\section{Dear Sir,}

Dr. Alcolado and colleagues have noted two potential biases in our study [1]. First, the nuclear families enrolled were not independent since they were drawn from 62 large pedigrees. The 54 diabetic sibships we studied were drawn from 39 of these large pedigrees (i. e., 15 of the sibships were in the same pedigrees as the remaining 39 sibships). The second limitation of our study was that a large number of the parents of these sibships could not be examined (and were thus excluded from the analysis), often because they were either deceased or could not be located. We agree with these comments. As Alcolado et al. note, in the ideal study both parents of randomly ascertained and unrelated diabetic and non-diabetic control individuals would be examined. Such a study is difficult to conduct, however, because the late onset of NIDDM makes it difficult to obtain a random sample of diabetic individuals whose parents have both been examined. An extended study period would be needed so that parents could be examined years before their offspring.

Alcolado and colleagues also draw attention to the relatively high prevalence of NIDDM observed in the parents of the diabetic sibships in our sample $(>60 \%)$ and compare these rates with those obtained from their population [2] and those from the Codiab group [3]. This comparison is not valid because the Alcolado and Codiab studies used proband reports to define parental diabetes status while we measured parental diabetes status directly. Moreover, our observed prevalence of

Corresponding author: Dr. B. Mitchell, Department of Genetics, Southwest Foundation for Biomedical Research, P.O. Box 28147, San Antonio, TX 78228-0147, USA
$60-65 \%$ is not unreasonable for the San Antonio MexicanAmerican population, in which the overall prevalence of NIDDM is relatively high. Among parents of the non-diabetic sibships in our sample the prevalence is $32 \%$ among mothers and $29 \%$ among fathers. These rates correspond closely to the overall prevalence of NIDDM among low-income MexicanAmericans estimated from the population-based San Antonio Heart Study, in whom prevalence is $30.8 \%$ (179/582) for individuals aged 50 years or over.

That maternal transmission of diabetes can occur is not in doubt. We do question however, the role of excess maternal transmission as a key feature of most NIDDM. Although a variety of studies (including one in our own Mexican-American population in San Antonio) have documented that diabetic individuals are more likely to report that their mother was diabetic than their father, this methodology could be biased if diabetes status in fathers was under-reported or under-diagnosed relative to the mothers' status. The fact that this observation has been replicated in multiple large studies could be attributed to the fact that this is a widely occurring bias; increasing the sample size will not attenuate the effect of the bias. Although our study has other potential biases, as Dr. Alcolado and colleagues correctly point out, it does not contain this particular bias. In our view, the importance of maternal transmission in NIDDM remains unresolved. Further insights may perhaps be gleaned by considering alternative study designs which, even if imperfect, are subject to different types of biases.

Yours sincerely,

B.D. Mitchell, C.M.Kammerer, L.J.Reinhart, M.P.Stern, J.W. MacCluer 


\section{References}

1. Mitchell BD, Kammerer CM, Reinhart LJ, Stern MP, MacCluer JW (1995) Is there an excess in maternal transmission of NIDDM? Diabetologia 38: 314-317
2. Alcolado JC, Alcolado R (1991) Importance of maternal history of non-insulin-dependent diabetic patients. BMJ 302: $1178-1180$

3. Thomas F, Balkau B, Vauzelle-Kervroedan F, Papoz L and the CODIAB Study Group (1994) Maternal effect and familial aggregation in NIDDM. Diabetes 43: 63-67

\section{Is oxidative stress the missing link between insulin resistance and atherosclerosis?}

\section{Dear Sir,}

It is noteworthy that the hypotheses which have been advocated to explain the pathogenesis of cardiovascular disease (CVD) have been largely focused on the atherogenic potential of insulin and glucose. Insulin, or more properly insulin resistance, i.e. the metabolic abnormality characterizing "syndrome X", has probably the most passionate supporters [1], but the evidence provided to affirm its involvement in the development of CVD is not univocal [2]. Independently of the blood insulin concentration and of the presence of diabetes, blood glucose level has been proven to be associated with CVD: subjects who have high-normal levels of blood glucose [3] and of glycated haemoglobin [4] but who are non-diabetic and non-insulin-resistant have an increased incidence of CVD.

When insulin resistance and glucose have been investigated separately, they have been demonstrated to act as independent determinants of several risk factors for CVD. Hypertension has been linked to insulin resistance [5], but data also support the hypothesis that it might be associated with an impaired carbohydrate metabolism [6]. The modifications of blood lipids typical of insulin resistance [1] are also present in patients with impaired glucose tolerance or diabetes [7]. Finally, plasma fibrinogen and PAI-1 concentrations have been shown to be increased in states of insulin resistance [8], but also during hyperglycaemia [9].

When two substances such as insulin and glucose, which appear so closely related physiologically, are implicated independently of each other in the development of CVD, it is legitimate to suspect that they may act by means of a third common mechanism.

It is now clear that impaired glucose metabolism leads to oxidative stress [10], and that the glycation of proteins produces free oxygen radicals [10]. The possibility that oxidative stress, i. e. the release of free radicals unbalanced by the protective effect of anti-oxidants, might have a pathogenetic role in the development of CVD has been recently raised [11]. Oxidative stress therefore might represent the biochemical mechanism through which the alteration of glucose metabolism might result in the development of CVD. Is it possible to also link such a mechanism to insulin resistance?

In our opinion, this sounds plausible. Preliminary findings in animal models indicate that rats with insulin resistance show signs of increased lipid peroxidation [12], while the administration of anti-oxidants improves the action of insulin in humans [13-14]. This last evidence is consistent with the finding that troglitazone, the structure of which is similar to that of vitamin $E$ [15], improves insulin-resistance in non-diabetic obese

Corresponding author: Dr. A. Ceriello, Department of Clinical and Experimental Medicine and Pathology, Chair of Internal Medicine, University of Udine, P.le S. Maria della Misericordia, I-33100 Udine, Italy subjects [16]. In adipocytes cultured in vitro, insulin increases the production of $\mathrm{H}_{2} \mathrm{O}_{2}$ [17], which has been shown to mimic the action of insulin [18]. Furthermore, the administration of vanadium reproduces the action of insulin [19] through the intercellular release of free radicals [20]. On the basis of this evidence, we propose oxidative stress as the best candidate for the role of final common mediator by which glucose and insulin resistance, via their action on risk factors, might contribute to the development of CVD. Experimental models of insulin resistance are available and it could be worth testing whether the administration of an anti-oxidant in this setting might result in the prevention of atherosclerosis and/or of its risk factors.

Yours sincerely,

A. Ceriello, M. Pirisi

\section{References}

1. Reaven GM, Laws A (1994) Insulin resistance, compensatory hyperinsulinaemia, and coronary heart disease. Diabetologia 37: 948-952

2. Jarrett RJ (1992) In defence of insulin: a critique of syndrome X. Lancet 340: 469-471

3. Yarnell JWG, Pickering JE, Elwood PC et al. (1994) Does non-diabetic hyperglycemia predict future IHD - evidence from the Caerphilly and Speedwell Studies. J Clin Epidemiol 47: 383-388

4. Singer DE, Natahn DM, Anderson KM, Wilson PWF, Evans JC (1992) Association of $\mathrm{Hb} \mathrm{A}_{1 \mathrm{c}}$ with prevalent cardiovascular disease in the original cohort of the Framingham Heart Study. Diabetes 41: 202-208

5. Ferrannini E, Natali A (1991) Essential hypertension, metabolic disorders, and insulin resistance. Am Heart J 121: 1274-1282

6. Ceriello A, Quatraro A, Giugliano D (1993) Diabetes mellitus and hypertension. The possible role of hyperglycaemia through oxidative stress. Diabetologia 36: 265-266

7. Fontbonne A, Eschwege E, Cambien F et al. (1989) Hypertriglyceridaemia as a risk factor of coronary heart disease mortality in subjects with impaired glucose tolerance or diabetes. Results from the 11-year follow-up of the Paris Prospective Study. Diabetologia 32: 300-304

8. Juhan-Vague I, Thompson SG, Jespersen J (1993) Involvement of the hemostatic system in the insulin resistance syndrome - a study of 1500 patients with angina pectoris. Arterioscler Thromb 13: 1865-1873

9. Ceriello A (1993) Coagulation activation in diabetes mellitus: the role of hyperglycaemia and therapeutic prospects. Diabetologia 36: 1119-1125

10. Ceriello A, Quatraro A, Giugliano D (1992) New insights on non-enzymatic glycosylation may lead to therapeutic approaches for the prevention of diabetic complications. Diabet Med 9: 297-299

11. Halliwell B (1993) Free radicals and vascular disease: how much do we know? BMJ 307: 885-886 